\title{
A novel and widely accessible HPLC method for determination content of homosalate in sunscreen products on the market
}

\author{
Belma Imamović* , Zinajda Bešić, Ervina Bečić \\ Department of Pharmaceutical Analytics, Faculty of Pharmacy, University of Sarajevo, Sarajevo, Bosnia and Herzegovina
}

\begin{abstract}
Introduction: Considering that the research has shown that homosalate acts as endocrine-active substance, it is very important to develop quick and sensitive method for tracking its concentrations in sunscreen products. The aim of this paper is to develop and validate the method for determining homosalate in sunscreen preparations and controlling the content of the products found on the market of Bosnia and Herzegovina.

Methods: A high-pressure liquid chromatography (HPLC) method for determination homosalate in sunscreen products has been developed and validated. Samples of six different manufacturers have been analyzed. HPLC method is a method of choice for this type of investigation.
\end{abstract}

Results: According to the calibration curve, it has been found that the proposed analytical method in a given range of concentration is linear and that the correlation coefficient is $R^{2}=0.9998$. Accuracy of the method is in the range of $94.26 \%-121.53 \%$. The results have shown that the homosalate concentration in the tested samples did not exceed the maximally permissible concentration (10\%). In the sample AV50, homosalate was not declared as an active ingredient, but it was identified and quantified at a concentration of $0.143 \%$.

Conclusion: Results of investigation of cosmetic products that are widely present on the market show the need of developing a sufficiently sensitive, easily accessible, analytical method for controlling the content of organic ultraviolet filters since the exceeding of the maximally permissible concentration can have a harmful effect on people who use these kinds of products. The results show that developed method meets conditions and is suitable for wide application.

Key words: Homosalate; HPLC; endocrine substance; cosmetic; validation

\section{INTRODUCTION}

Sunscreen products are dermal application products designed to protect skin from ultraviolet (UV)

\footnotetext{
*Corresponding author: Belma Imamović, Department of Pharmaceutical Analytics, Faculty of Pharmacy, University of Sarajevo, Zmaja od Bosne 8, 71000 Sarajevo, Bosnia and Herzegovina. E-mail: belma_i@yahoo.com
}

Submitted: 22 October 2017/Accepted: 30 November 2017 radiation and the harmful effects it causes. They consist of various ingredients, of which the active components are UV filters. The active ingredients of sunscreen preparations are specially designed molecules, protective UV filters, which have the ability to absorb, reflect, or disperse radiation from the UV part of the spectrum. Increasing UV filter concentration in sunscreen products not only increases UV protection but also increases their toxicity and decreases their cosmetic acceptability. An ideal 
sunscreen preparation must provide high protection that is equally effective against UVA and UVB radiation (1). UV filters can be divided according to working method, that is, the mode of interaction with UV radiation photons. Based on this, they are divided into physical or mechanical UV filters and chemical UV filters or UV absorbers. Physical UV filters primarily not only reflect and disperse UV radiation but also absorb a certain amount of radiation. Chemical UV filters mainly absorb UV radiation that comes into contact with the skin (2). Cosmetic products containing these compounds are usually better accepted than those formulated with physical UV filters due to a more suitable application (3).

Homosalate standard (HS) is a chemical UV filter that belongs to the group of salicylates. Salicylates are weak UV radiation absorbers and are usually used in combination with other UV filters to increase protection (4). Therefore, homosalate is added to sunscreen products not only to increase the protection against UV radiation but also to reduce the photodegradation of other ingredients in the preparation (5). Homosalate is a mixture of isomers, where one isomer is present to the larger extent than the other. There are two isomers of homosalate, and usually used mixtures are $15 \%$ of cis and $85 \%$ of transform, as well as $40 \%$ of cis and $60 \%$ of transform (6). Homosalate absorbs UVB radiation in the wavelength range of 280-315 nm (maximum absorption is at $306 \mathrm{~nm}$ ). It is widely present as an active ingredient in sunscreen cosmetics, such as creams, gels, lotions, sprays, and other dermal application cosmetic products. The maximum permitted concentration of homosalate in market products is regulated by law up to $15 \%$ in the USA and Australia and up to $10 \%$ in the EU and Japan (7). In the past few years, studies have shown that some UV filters can alter endocrine signaling by mimicking or inhibiting the action of the hormones. Homosalate belongs to these UV filters that are classified as endocrine-active substances (8). Studies have also shown that the homosalate exhibits estrogenic and antiandrogenic activity. It is known that homosalate significantly increases the proliferation of MCF-7 breast cancer cells and the secretion of estrogen-regulated protein $\mathrm{pS} 2$, demonstrating in vitro evidence of estrogenic activity (9). Homosalate is a lipophilic substance $\left(\log \mathrm{P}_{\mathrm{o} / \mathrm{v}}=5.94\right)$ that shows a high binding affinity for the lipid components of the skin layers. However, the amount of absorption depends on the amount of sunscreen applied to the skin and the concentration of homosalate in sunscreen. Since homosalate has the potential of dermal penetration with proven absorption through the skin (10) and excretion through breast milk (11), it is very important to develop an analytical method for monitoring the content of homosalate in commercially available sunscreen preparations. Control of cosmetic products in Bosnia and Herzegovina not only consists of controlling the content of heavy metals and its microbiological purity but should also include the control of the content of organic UV filters since the exceeding of the maximally permissible concentration can have a harmful effect on people who use these kinds of products (12).

Methods suggested in recent literature request complex equipment that is not accessible to the majority of laboratories (13). The aim of each analyst is to have simple, sensitive, and accessible method for rapid determination of the content of organic UV filters of sunscreen products available on the market. High-precision chromatography is the method of choice in this type of test.

\section{METHODS}

\section{Standard, sample, chemical, and reagents}

HS was purchased from Merck (Germany). Samples were taken from products found widely in Bosnia and Herzegovina. All solvents were of an analytical grade. The chemicals and reagents used were acetonitrile (HPLC grade: Sigma-Aldrich, Germany), formic acid (Fisher Scientific, USA), polysorbate-80 (Tween-80, Semikem, Bosnia and Herzegovina), and purified water for HPLC.

\section{Chromatographing condition}

Separation was performed using HPLC system (Shimadzu, Japan) and column Zorbax Eclipse XDB C18, 3.5 $\mu \mathrm{m}$ from Agilent (USA). Separation was performed using gradient chromatographing. The used mobile phases were: Solution A (water $+0.1 \%$ formic acid) and solution B (acetonitrile $+1 \%$ formic acid). $306 \mathrm{~nm}$ wavelength was used. 
The program of performed gradient elution is shown in Table 1.

\section{Stock solution}

Stock homosalate solution was prepared by taking $100 \mu \mathrm{L}$ of $\mathrm{HS}$, transferred to a $10 \mathrm{~mL}$ volumetric flask, and filled with acetonitrile to the mark. The concentration of the prepared standard solution was $10.45 \mathrm{mg} / \mathrm{mL}$.

\section{Working solutions}

The working solution 1 , in $2.09 \mathrm{mg} / \mathrm{mL}$ concentration used for the preparation of the samples by the standard addition method, was prepared by diluting the stock HS solution in acetonitrile with 1:4 ratio. Working solution 2 , in $1 \mathrm{mg} / \mathrm{mL}$ concentration used to prepare the solution for the calibration curve, was prepared by taking $478 \mu \mathrm{L}$ solutions of the stock HS and $522 \mu \mathrm{L}$ of acetonitrile (total of $1 \mathrm{~mL}$ ). The stock and working solutions were stored in amber vials and protected from light in the fridge on $+4^{\circ} \mathrm{C}$.

\section{Series of working solutions for calibration curve}

Series of working solutions for calibration curve were prepared by taking exact quantities of working solution 2 and diluting it in acetonitrile to a specific volume. Solutions series were prepared in concentrations as follows: $1 \mu \mathrm{g} / \mathrm{mL}, 5 \mu \mathrm{g} / \mathrm{mL}$, $10 \mu \mathrm{g} / \mathrm{mL}, 20 \mu \mathrm{g} / \mathrm{mL}, 30 \mu \mathrm{g} / \mathrm{mL}, 40 \mu \mathrm{g} / \mathrm{mL}, 50 \mu \mathrm{g} /$ $\mathrm{mL}, 60 \mu \mathrm{g} / \mathrm{mL}, 75 \mu \mathrm{g} / \mathrm{mL}, 100 \mu \mathrm{g} / \mathrm{mL}, 150 \mu \mathrm{g} / \mathrm{mL}$, and $200 \mu \mathrm{g} / \mathrm{mL}$.

\section{Preparation of samples for HPLC analysis}

Samples for analysis were taken from six different manufacturers. Seven samples of sunscreen preparations with different sun protection factor values were prepared for the analysis. All samples

TABLE 1. The program of gradient elution

\begin{tabular}{lcc}
\hline Time $(\mathrm{min})$ & Solution B $(\%)$ & Flow $(\mathrm{mL} / \mathrm{min})$ \\
\hline 0.00 & 70 & 0.5 \\
0.1 & 70 & 0.5 \\
20 & 0 & 0.5 \\
25 & 0 & 0.5 \\
25.1 & 70 & 0.5 \\
30 & 70 & 0.5 \\
\hline
\end{tabular}

for the analysis were prepared by weighing $1 \mathrm{~g}$ of each sample directly into $100 \mathrm{~mL}$ volumetric flask (Sample A). $0.5 \mathrm{~mL}$ of polysorbate- 80 and $60 \mathrm{~mL}$ of acetonitrile were added to each flask. The solutions were mixed by a magnetic mixer for $1 \mathrm{~h}$ at $60^{\circ} \mathrm{C}$. After cooling, each solution was filled with acetonitrile to the mark. The solutions were filtered through a $0.45 \mu \mathrm{m}$ pore size non-polar filter. $1 \mathrm{~mL}$ of each sample filtrate was poured into $10 \mathrm{~mL}$ volumetric flask and filled with acetonitrile to the mark (Sample B). $490 \mu \mathrm{L}$ of Sample B was diluted with $10 \mu \mathrm{L}$ of acetonitrile (total of $500 \mu \mathrm{L}$ ) (Sample C). Samples with stock standard additive (spike samples) were prepared from $490 \mu \mathrm{L}$ of working solution diluted with $10 \mu \mathrm{L}$ of stock solution. The concentration of the stock solution additive was $0.0418 \mathrm{mg} / \mathrm{mL}$. For analysis, $10 \mu \mathrm{L}$ of Sample C was injected into the HPLC system. Concentrations were read from the calibration curve, and the final concentration of the homosalate in the samples was calculated by the expression:

$$
\mathrm{x}=\mathrm{C} \times \frac{0.5 \mathrm{~mL} \times 10 \mathrm{~mL} \times 100 \mathrm{~mL}}{0.49 \mathrm{~mL} \times 1 \mathrm{~mL} \times 1 \mathrm{~g}}
$$

$\mathrm{x}$ - Final concentration of homosalate in samples $(\mathrm{g} / 100 \mathrm{~mL})$

C - Concentration of homosalate read from calibration curve $(\mathrm{g} / 100 \mathrm{~mL})$.

\section{RESULTS}

\section{Optimization of chromatographingconditions}

The first step in the development of the analytical method for the identification and quantification of homosalate was to determine the maximum absorption of homosalate and the degree of purity of the HS. For this, UV spectrum of homosalate was recorded in the wavelength range of 200-600 nm (Figure 1a and $\mathrm{b}$ ).

After establishing the purity of the HS, the stationary and the mobile phase for identification and quantification of the homosalate was selected. For this purpose, a HS of the concentration of $10 \mu \mathrm{g} / \mathrm{mL}$ was used. The wavelength of the identification and quantification was $306 \mathrm{~nm}$. Chromatography was performed on the stationary phase C18 with gradient elution with the mobile phase: Solution 
A (water $+0.1 \%$ formic acid) and Solution B (acetonitrile $+1 \%$ formic acid).

\section{Validation of HPLC method for identification and quantification of homosalate}

After optimization of the HPLC analytical method for identification and quantification of homosalate, the validation process was performed according to the ICH directives: Validation of Analytical Procedures: Text and Methodology, Q2 (R1) (12). The following parameters were validated: Selectivity, range of linearity, accuracy, repeatability, precision, the limit of detection (LD), and the limit of quantification (LQ). All data were statistically processed by calculating the mean value, standard deviation (SD), and the coefficient of variation $(\mathrm{CV})$.

\section{Selectivity of the analytical method}

The selectivity of the analytical method was tested by comparing the blank sample chromatogram (Figure 2a), the chromatogram of the HS (Figure 2b), and the chromatogram of the homosalate containing sample at $306 \mathrm{~nm}$ (Figure 2c).

\section{Repeatability and linearity of the analytical method}

Repeatability of the analytical method was done by recording each concentration of HS solutions prepared for calibration on the same day. Intermediate precision was determined by recording the selected concentrations after both 24 and 32 h. Each concentration was recorded 3 times. The mean value for the areas below the signal $\left(A_{1}, A_{2}\right.$, and $\left.A_{3}\right), S D$, and the $\mathrm{CV}$ for each concentration were calculated (Table 2).
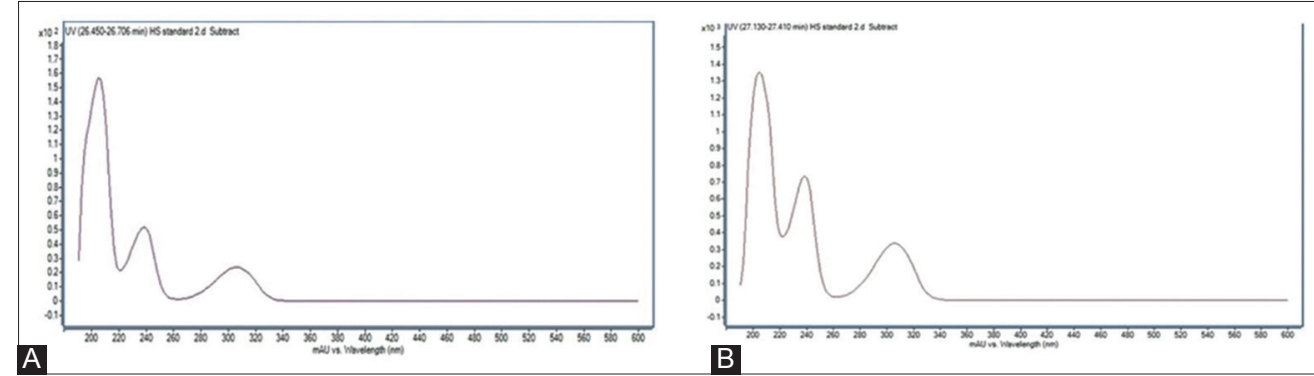

FIGURE 1. Determination of the maximum absorption of homosalate and the degree of purity of the homosalate standard. Ultraviolet spectrum of homosalate trans-isomer trans-homosalate standard (HS) (A) and cis-isomer cis-HS (B) was recorded at a wavelength range of $200-600 \mathrm{~nm}$.

TABLE 2. Areas read from the HS chromatogram and calculated AM value, SD, and the CV

\begin{tabular}{lcccccc}
\hline Concentrations $\mu \mathrm{g} / \mathrm{mL}$ & $\mathrm{A}_{1}$ & $\mathrm{~A}_{2}$ & $\mathrm{~A}_{3}$ & $\mathrm{AM}$ & $\mathrm{SD}$ & $\mathrm{CV} \%$ \\
\hline 1 & 36,307 & 36,875 & 36,591 & $36,591.00$ & 284.00 & 0.78 \\
5 & 95,876 & 96,452 & 96,164 & $96,164.00$ & 288.00 & 0.30 \\
10 & 196,080 & 196,875 & 196,478 & $196,477.50$ & 397.50 & 0.20 \\
20 & 388,638 & 391,111 & 389,875 & $389,874.50$ & $1,236.50$ & 0.32 \\
30 & 640,389 & 639,654 & 640,022 & $640,021.50$ & 367.50 & 0.06 \\
40 & 840,670 & 844,285 & 842,478 & $842,477.50$ & $1,807.50$ & 0.21 \\
50 & $1,065,171$ & $1,064,413$ & $1,064,792$ & $1,064,792.00$ & 379.00 & 0.04 \\
60 & $1,257,460$ & $1,255,053$ & $1,256,257$ & $1,256,256.67$ & $1,203.50$ & 0.10 \\
75 & $1,588,965$ & $1,583,954$ & $1,586,460$ & $1,586,459.67$ & $2,505.50$ & 0.16 \\
100 & $2,151,566$ & $2,143,816$ & $2,147,691$ & $2,147,691.00$ & $3,875.00$ & 0.18 \\
150 & $3,172,923$ & $3,179,612$ & $3,176,268$ & $3,176,267.67$ & $3,344.50$ & 0.11 \\
200 & $4,307,544$ & $4,321,775$ & $4,314,660$ & $4,314,659.67$ & $7,115.50$ & 0.16 \\
\hline
\end{tabular}

AM: Arithmetic mean; SD: Standard deviation; CV: Coefficient of variation 
Furthermore, repeatability (intermediate precision) was performed after $24 \mathrm{~h}$ and $32 \mathrm{~h}$ on the specific concentrations of HS (Tables 3 and 4).

\section{Linearity}

The linearity of the analytical method is tested through a concentration range of $1-200 \mu \mathrm{g} / \mathrm{mL}$ of the HS. A calibration curve was constructed, and the equation line was obtained which was used to read the concentration of the homosalate in the samples (Figure 3).

\section{Accuracy of the analytical method}

The accuracy of the analytical method was done using the standard addition method, that is, a wellknown concentration of HS $(0.0418 \mathrm{mg} / \mathrm{mL})$ was added to each sample. Tested samples do not have an exact concentration of homosalate declared, so the accuracy was done as presented. The samples with unknown concentration of homosalate were recorded as well as the samples with wellknown concentration of the added HS. The difference between AM of the areas of samples with well-known homosalate concentration $\left(\mathrm{P}_{\text {ssu }}\right)$ and the area of samples without standard addition $\left(\mathrm{P}_{\text {su }}\right)$ made the area corresponding to the concentration of added homosalate. According to the established concentration, the accuracy of the analytical method was obtained for each tested sample and expressed as a recovery value (Table 5).

\section{Determination homosalate content in tested samples}

After validation, the analytical method for identification and quantification of homosalate through the parameters of selectivity, linearity, repeatability, accuracy, $\mathrm{LD}$ and $\mathrm{LQ}$, the determination of the homosalate content in the tested samples was initiated. Analysis was performed on six samples of sunscreen preparations available on the market of Bosnia and Herzegovina where homosalate content was declared and one sample in which homosalate was not declared as an active ingredient. Samples were recorded with the developed method, and chromatograms of samples were obtained (Figure 4a-g). Each sample was recorded 3 times. The surface of trans-HS isomers

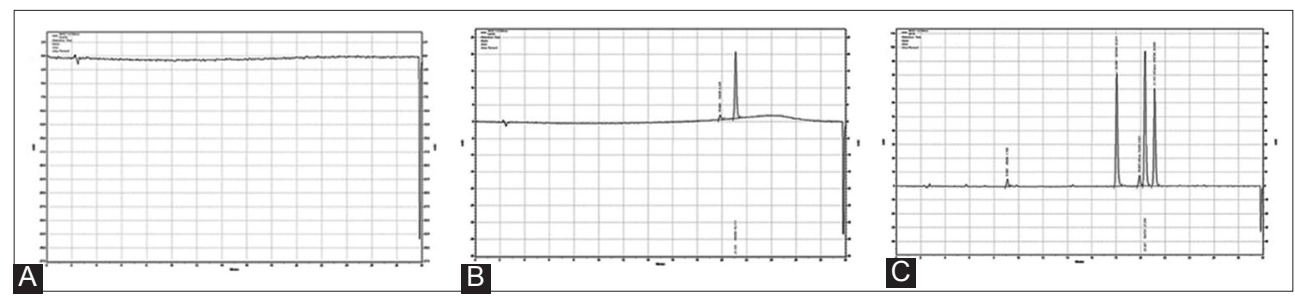

FIGURE 2. Selectivity of the analytical method was tested by comparing the blank sample chromatogram (A), the chromatogram of the homosalate standard (B), and the chromatogram of the homosalate containing sample at $306 \mathrm{~nm}(\mathrm{C})$.

TABLE 3. Repeatability after $24 \mathrm{~h}$

\begin{tabular}{lcccccc}
\hline Concentrations $\mu \mathrm{g} / \mathrm{mL}$ & $\mathrm{A}_{1}$ & $\mathrm{~A}_{2}$ & $\mathrm{~A}_{3}$ & $\mathrm{AM}$ & $\mathrm{SD}$ & $\mathrm{CV} \%$ \\
\hline 30 & 652,121 & 646,821 & 645,711 & $648,217.67$ & $3,425.64$ & 0.53 \\
60 & $1,261,823$ & $1,264,569$ & $1,265,523$ & $1,263,971.67$ & $1,920.96$ & 0.15 \\
100 & $2,150,223$ & $2,158,295$ & $2,149,995$ & $2,152,837.67$ & $4,727.56$ & 0.22 \\
200 & $4,319,578$ & $4,327,537$ & $4,325,538$ & $4,324,217.67$ & $4,140.52$ & 0.10 \\
\hline
\end{tabular}

AM: Arithmetic mean; SD: Standard deviation; CV: Coefficient of variation

TABLE 4. Repeatability after $32 \mathrm{~h}$

\begin{tabular}{lcccccc}
\hline Concentrations $\mu \mathrm{g} / \mathrm{mL}$ & $\mathrm{A}_{1}$ & $\mathrm{~A}_{2}$ & $\mathrm{~A}_{3}$ & $\mathrm{AM}$ & $\mathrm{SD}$ & $\mathrm{CV} \%$ \\
\hline 30 & 644,839 & 650,602 & 649,332 & $648,257.67$ & $3,027.98$ & 0.47 \\
60 & $1,265,558$ & $1,263,295$ & $1,264,955$ & $1,264,602.67$ & $1,171.92$ & 0.09 \\
\hline
\end{tabular}

AM: Arithmetic mean; SD: Standard deviation; CV: Coefficient of variation 


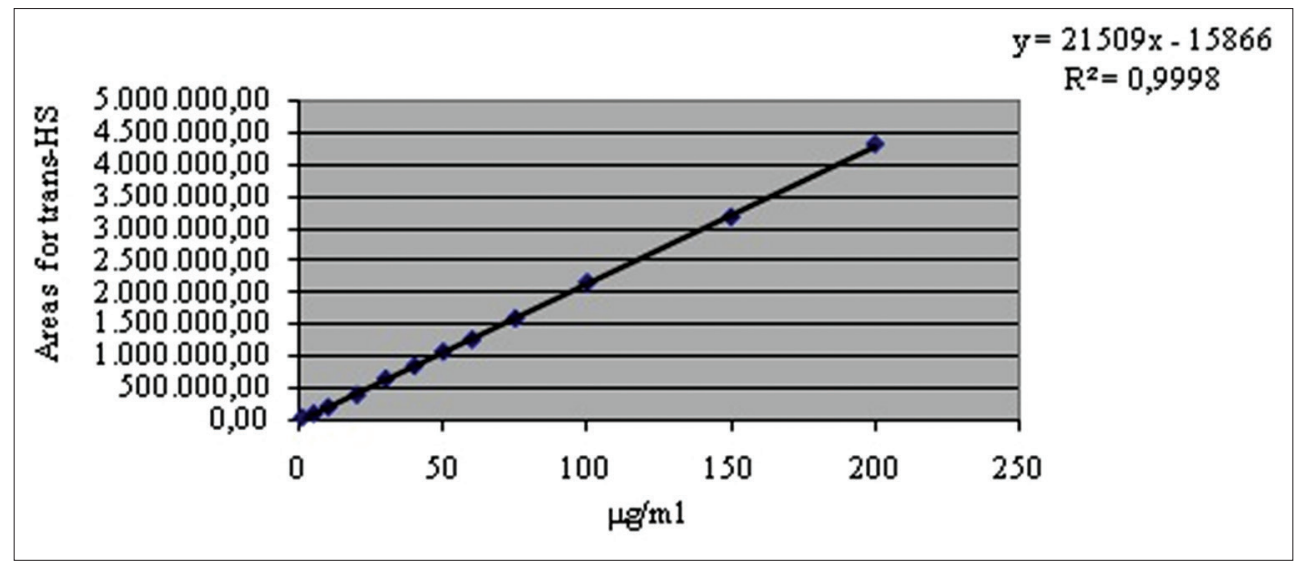

FIGURE 3. Calibration curve for homosalate. The linearity of the analytical method was tested through a concentration range of $1-200 \mu \mathrm{g} / \mathrm{mL}$ of the homosalate standard.

TABLE 5. Measured samples areas, calculated arithmetic mean, difference between areas, concentration, and recovery

\begin{tabular}{lccccccc}
\hline Samples & $\mathrm{A}_{1}$ & $\mathrm{~A}_{2}$ & $\mathrm{~A}_{3}$ & $\mathrm{AM}$ & Assu-Asu & Concentration & $R \%$ \\
\hline AV50 & 13,556 & 13,661 & 14,562 & 13,926 & 933,932 & 0.0442 & 105.74 \\
AV50 spiked & 946,652 & 947,392 & 949,531 & 947,858 & & & \\
EU30 & 454,525 & 461,116 & 458,226 & 457,956 & 927,104 & 0.0438 & 104.89 \\
EU30 spiked & $1,379,106$ & $1,376,932$ & $1,399,142$ & $1,385,060$ & & & \\
LP50 & 897,733 & 897,430 & 901,268 & 898,810 & 994,341 & 0.0469 & 112.2 \\
LP50 spiked & $1,894,154$ & $1,889,545$ & $1,895,754$ & $1,893,151$ & & & \\
MB30 & $1,123,027$ & $1,121,745$ & $1,134,380$ & $1,126,384$ & 974,731 & 0.0461 & 110.23 \\
MB30 spiked & $2,096,682$ & $2,093,462$ & $2,113,202$ & $2,101,115$ & & & \\
M215 & 695,785 & 698,201 & 702,624 & 698,870 & 830,825 & 0.0394 & 94.26 \\
M215 spiked & $1,524,949$ & $1,525,329$ & $1,538,807$ & $1,529,695$ & & & \\
NK50 & $1,448,149$ & $1,441,947$ & $1,473,516$ & $1,454,537$ & $1,075,943$ & 0.0508 & 121.53 \\
NK50 spiked & $2,512,732$ & $2,511,905$ & $2,566,803$ & $2,530,480$ & & & \\
OS12 & 721,312 & 724,157 & 735,117 & 726,862 & 951,959 & 0.045 & 107.65 \\
OS12 spiked & $1,675,529$ & $1,677,777$ & $1,683,157$ & $1,678,821$ & & & \\
\hline A Areas of samp & with well-known homosate & & & & \\
\end{tabular}

$\mathrm{A}_{\mathrm{ssu}}$ : Areas of sample with well-known homosalate concentration; $\mathrm{A}_{\mathrm{su}}$ : Areas of samples without standard addition. AM: Arithmetic mean

in samples was read; mean surface area, SD, and the $\mathrm{CV}$ were calculated. Based on the arithmetic mean of areas of the trans-HS isomers, the concentrations of homosalate in all samples were read from the calibration curve. The final content of homosalate was calculated for all the tested samples (Table 6).

\section{DISCUSSION}

To optimize the analytical method, a spectrum of HS was recorded to determine the maximum absorption and its purity. The HS purity was not declared, and it is known from the literature that comes as a mixture of cis-and trans-isomers (5). It has been
TABLE 6. Homosalate concentrations read from samples

\begin{tabular}{lccc}
\hline Samples & AM & Read g/ml & Calculated content (\%) \\
\hline AV50 & 13,926 & 1.399 & 0.143 \\
EU30 & 457,956 & 22.04 & 2.359 \\
LP50 & 898,810 & 42.53 & 4.772 \\
MB30 & $1,126,384$ & 53.11 & 5.854 \\
M215 & 698,870 & 33.24 & 3.133 \\
NK50 & $1,454,537$ & 68.36 & 8.310 \\
OS12 & 726,862 & 34.54 & 3.720 \\
\hline
\end{tabular}

AM: Arithmetic mean

found that standard has the maximum absorption at $238 \mathrm{~nm}$ and $306 \mathrm{~nm}$ (Figure 1a and b). At a wavelength of $306 \mathrm{~nm}$, the share of trans-isomers 

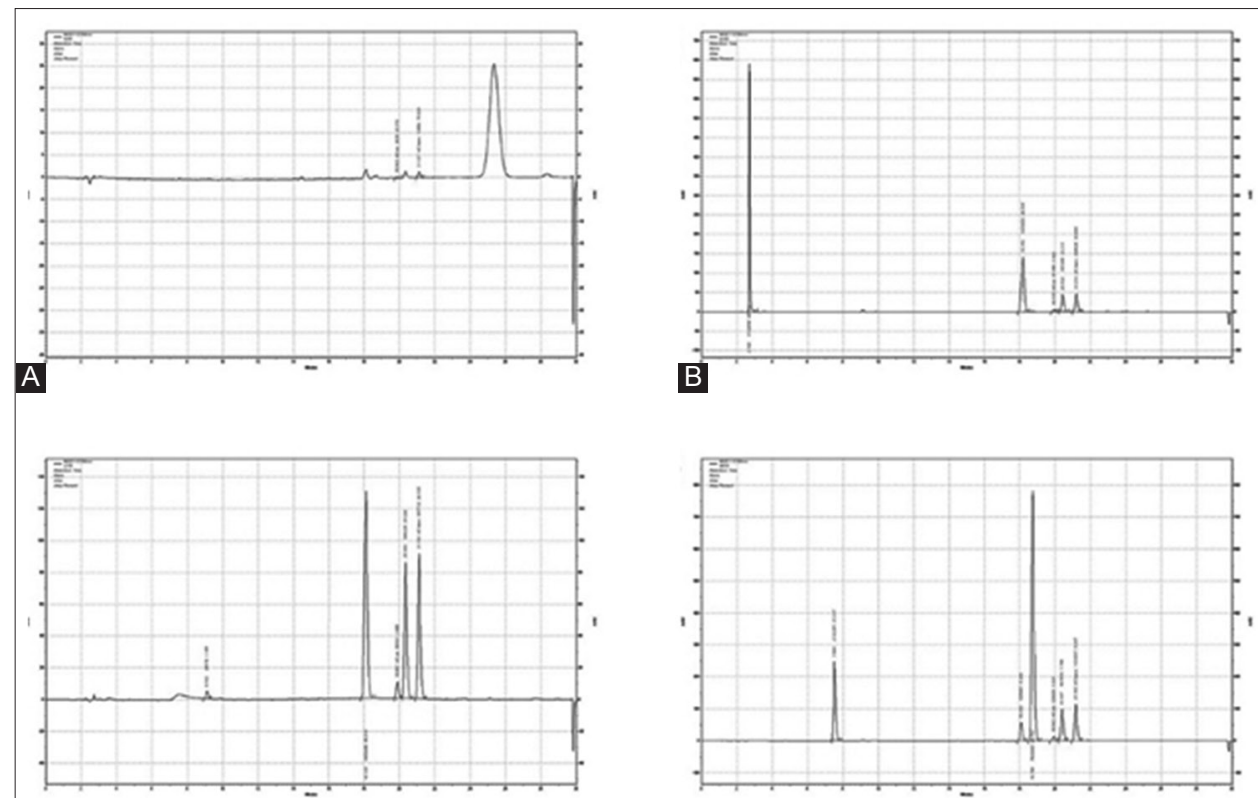

C
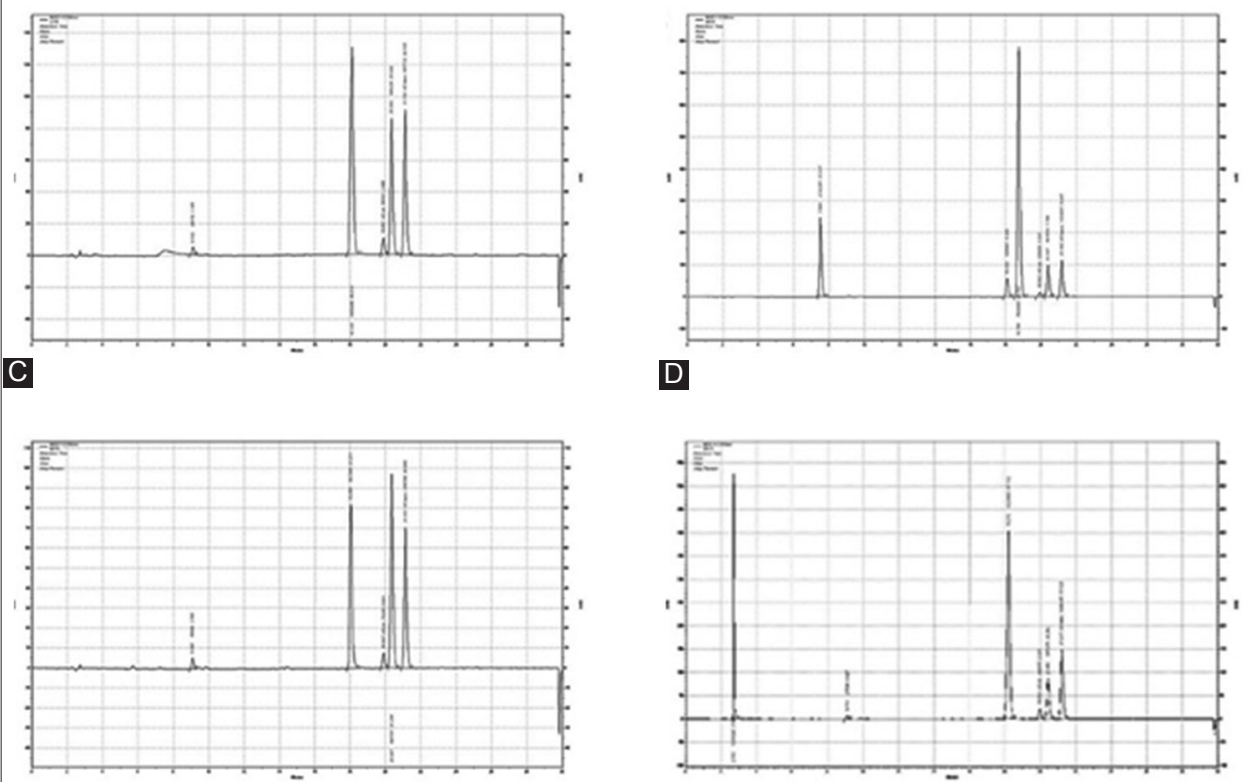

E

\section{D}

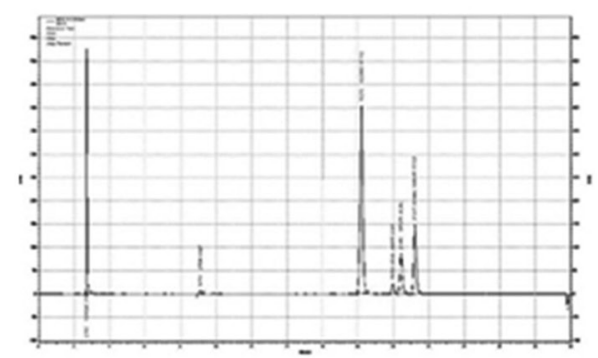

$\mathbf{F}$

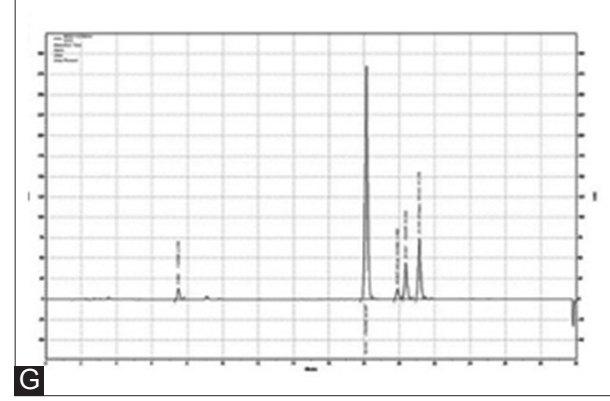

FIGURE 4. Analysis of six samples of sunscreen preparations available on the market of Bosnia and Herzegovina. Chromatogram of sample AV50 (a), sample EU30 (b), sample LP50 (c), sample MB30 (d), sample MZ15 (e), sample NK50 (f), sample OS1 (g).

is $94.189 \%$ and the share of cis isomer is $5.811 \%$. The response of cis and trans-isomers was observed at wavelengths of $285 \mathrm{~nm}$ and $311 \mathrm{~nm}$, to determine the purity of the response (signal-noise ratio).
The purity of the response factor at the wavelengths used or at any other two wavelengths, when it comes to geometric isomers, has to be similar. The ratio at $285 \mathrm{~nm} / 311 \mathrm{~nm}$ for cis-HS was 0.502 and for 
trans-HS 0.506. The same method was used to check the purity of each sample to determine whether an unknown analyte interacts with the target analyte. In the case of interaction, this ratio is significantly changed.

From the chromatogram of the standard (Figure 2b), it has been found that cis-HS and trans-HS are well separated and have sharp peaks on the chromatogram. Retention time for cis-HS is $19.860 \mathrm{~min}$ and for trans-HS is $21.103 \mathrm{~min}$. From the HS chromatogram, it can be concluded that this method can be used in the process of identification and quantification of homosalate. On the basis of previous data about cis-HS and trans-HS isomers percentage ratio, it was decided to monitor trans-HS to determine homosalate content because trans-HS was present in a much higher percentage than cis-HS. On the chromatogram of the blank test (Figure 3), it is notable that there are no peaks at the retention times of the cis- and trans-homosalate isomers that would interfere with their peaks in the standard and sample during the analysis. To use the method for identifying and determining homosalate in the tested samples, the method was validated for selectivity, range of linearity, accuracy, repeatability, precision, LD, and LQ. It has been found that the proposed HPLC method for the identification and quantification of homosalate is selective. From the intermedia precision, it is evident that the analytical method for identification and quantification of homosalate is reproducible after $24 \mathrm{~h}$ and $32 \mathrm{~h}$ as well (Tables 3 and 4).

Based on the calibration curve (Figure 3), we have found that the proposed analytical method is linear in given range of the concentration and that the coefficient of correlation is $R^{2}=0.9998$, which shows the exceptionally high linearity of the method. From the calibration curve, the values for the LD and the LQ were calculated.

For homosalate, the se values are

$\mathrm{LD}=0.01426385 \mu \mathrm{g} / \mathrm{mL}$ and $\mathrm{LQ}=0.04754616 \mu \mathrm{g} / \mathrm{mL}$.

The accuracy of the analytical method ranges from $94.26 \%$ to $121.53 \%$ (Table 5 ), depending on the type of analyzed sample. After the method was validated, determination of the homosalate content in the tested samples was performed. On the basis of the obtained data (Table 6), it is visible that the concentrations of the homosalate in the tested samples: EU30, LP50, MB30, MZ15, NK50, and OS12 do not exceed the maximally permissible concentration (10\%). In the tested AV50 sample, homosalate was not declared as an active ingredient, but during the analysis, it was identified and quantified at a concentration of $0.143 \%$.

\section{CONCLUSION}

Presented results show that the analytical method used enables identification and determination of homosalate in the presence of other substances in sunscreen products. The advantage of this analytical method compared with homosalate identification data published in literature is the high sensitivity and low CV that show good reproducibility of this method. Low CV, low detection, and quantification limits enable accurate and reliable quantification of homosalate in cosmetic sunscreen products. In addition, it is the fact that sample preparation is simple and easy feasible despite the complex formulation of cosmetic products. The concentration of homosalate does not exceed the maximally allowed concentration in all tested samples. Homosalate, as the active ingredient, was not declared in the tested sample AV50, but it was identified and quantified with the method used. The data indicate the need for controlling these types of products that are widely present at the market. In addition to the content of heavy metals and microbiological purity, the product control should also include the control of the content of organic UV filters directly responsible for the UV radiation protection level.

\section{REFERENCES}

1. Manová E, von Goetz N, Hauri U, Bogdal C, Hungerbühler K. Organic UV filters in personal care products in Switzerland: A survey of occurrence and concentrations. Int J Hyg Environ Health. 2013;216(4):508-14.

https://doi.org/10.1016/j.ijheh.2012.08.003.

2. Serpone N, Dondi D, Albini A. Inorganic and organic UV filters: Their role and efficacy in sunscreens and suncare products. Inorg Chim Acta. 2007;360:794-80.

https://doi.org/10.1016/j.ica.2005.12.057

3. Lim H, Draelos Z. Clinical Guide to Sunscreens and Photoprotection (Basic and Clinical Dermatology). New York: Informa Healthcare; 2009. p. 11-53.

4. U.S. Department of Health and Human Services. Household Product Database. Available from: http://hpd.nlm.nih.gov. [Last cited on 2018 Apr 15].

5. Nicholas J. Sunscreens: Development: Evaluation, and Regulatory Aspects. Boca Raton: CRC Press; 1996. 
6. Krause M, Klit A, Jensen MB, Soeborg T, Frederiksen H, Schlumpf M, et al. Sunscreens: Are they beneficial for health? An overview of endocrine disrupting properties of UV-filters. Int J Androl. 2012;35(3):424-36.

https://doi.org/10.1111/j.1365-2605.2012.01280.x.

7. Selma Y, Merve B, Ufuk B. Toxicological profile of homosalate as cosmetic ingredients. Glob J Pathol Microbiol. 2013;1:7-11.

8. Ruszkiewicz JA, Pinkas A, Ferrer B, Peres TV, Tsatsakis A, Aschne M. Neurotoxic effect of active ingredients in sunscreen products, a contemporary review. Toxicol Rep. 2017;4:245-59.

https://doi.org/10.1016/j.toxrep.2017.05.006.

9. Chatelain E, Gabard B, Surber C. Skin penetration and sun protection factor of five UV filters: Effect of the vehicle. Skin Pharmacol Appl Skin Physiol. 2003;16(1):28-35. https://doi.org/10.1159/000068291.

10. Schlumpf M, Kypke K, Wittassek M, Angerer J, Mascher H, Mascher D, et al. Exposure patterns of UV filters, fragrances, parabens, phthalates, organochlor pesticides, PBDEs, and PCBs in human milk: Correlation of UV filters with use of cosmetics. Chemosphere. 2010;81:1171-83.

https://doi.org/10.1016/j.chemosphere.2010.09.079.

11. Molins-Delgado D, Olmo-Campos MDM, Valeta-Juan G, PleguezuelosHernández V, Barceló D, Díaz-Cruz MS, et al. Determination of UV filters in human breast milk using turbulent flow chromatography and babies' daily intake estimation. Environ Res. 2018;161:532-9.

https://doi.org/10.1016/j.envres.2017.11.033.

12. Wang J, Pan L, Wu S, Lu L, Xu Y, Zhu Y, et al. Recent advances on endocrine disrupting effects of UV filter. Int J Environ Res Public Health. 2016;13(8):782

https://doi.org/10.3390/ijerph13080782.

13. Meng X, Ma Q, Bai H, Wang Z, Han C, Wang C, et al. Simultaneous separation and determination of 15 organic UV filters in sunscreen cosmetics by HPLC-ESI-MS/MS. Int J Cosmet Sci. 2017;39(4):386-92.

https://doi.org/10.1111/ics.12387. 